\title{
Pengaruh Metode Show And Tell Terhadap Kemampuan Berbicara Pada Anak Usia Dini
}

\author{
Ni Nyoman Ari Ratnadi', Kadek Devy Marleni' ${ }^{2}$, Kadek Dwi Arlinayanti ${ }^{3}$ \\ ${ }^{1,2.3}$ Sekolah Tinggi Ilmu Kesehatan Buleleng, Bali, Indonesia
}

Email: ariratnadi@gmail.com

\begin{abstract}
ABSTRAK
Metode show and tell adalah kegiatan menunjukan sesuatu kepada audiens dan mendeskripsikan sesuatu. Pada awalnya anak akan membawa benda-benda pribadi dari rumah dan menjelaskan secara sederhana, seperti nama benda dan bagaimana mereka mendapatkan benda tersebut. Tujuan dari penelitian ini adalah untuk mengetahui pengaruh metode show and tell terhadap peningkatan kemampuan berbicara pada anak usia 4-5 tahun di PAUD Pelita Kasih Singaraja. Desain penelitian menggunakan pra- eksperimental dengan rancangan one group pre-post test design. Populasi yang digunakan dalam penelitian ini adalah anak usia 4-5 tahun di PAUD Pelita Kasih Singaraja Bali. Besar sampel yang digunakan adalah 30 responden yang telah dipilih dengan menggunakan teknik sampling total sampling. Pengukuran kemampuan berbicara dikumpulkan dengan menggunakan lembar observasi yang berpedoman pada tugas-tugas menurut usia di Denver II. Penelitian ini menggunakan statistik parametrik menggunakan uji Paired Sample T-test dengan taraf signifikan $\alpha=0,05$. Hasil penelitian menunjukkan bahwa terdapat Pengaruh Metode Show And Tell Terhadap Peningkatan Kemampuan Berbicara Pada Anak Usia 4-5 Tahun di PAUD Pelita Kasih Singaraja.
\end{abstract}

Kata Kunci: Metode Show And Tell; Kemampuan Berbicara; Anak

\begin{abstract}
Show and tell method is an activity used for showing something to the audiences and explains it. The children will bring personal items from their house and explain in a simple way which is included the name of the object and how they got the object. The research aimed to find out the influence of show and tell method on increasing speaking ability in children 4-5 years old in Pelita Kasih Kindergarten Singaraja. The research method used in this research was pre-experimental along with the one group pre-post test design. The subjects of the study were the children aged 4-5 years old in Pelita Kasih Kindergarten Singaraja. There were 30 respondents involved in this study. The sampling technique employed in this study was total sampling. There were 30 respondents were involved in this study. The students' speaking ability was measured through observation checklist. The observation checklist was developed based on Denver II's theory. This research used Paired Sample T-Test, with significant level $\alpha=0,05$. The result shows that show and tell method can improve students' speaking ability of the children aged 4-5 years old in PAUD Pelita Kasih Singaraja.
\end{abstract}

Keywords: Show and Tell Method; Speaking Ability; Children

(C) 2021 Ni Nyoman Ari Ratnadi, Kadek Devy Marleni, Kadek Dwi Arlinayanti Under the license CC BY-SA 4.0

Pedagogika.fip@ung.ac.id P-ISSN: 2086-4469 E-ISSN: 2716-0580 


\section{PENDAHULUAN}

Pendidikan anak usia dini (PAUD) adalah suatu pelayanan pendidikan yang ditujukan kepada anak sejak lahir sampai anak usia enam tahun dengan melakukan upaya pembinaan melalui pemberian rangsangan pendidikan untuk membantu perkembangan dasar-dasar pengetahuan, sikap, dan keterampilan pada anak agar anak memiliki kesiapan dalam memasuki pendidikan ke jenjang selanjutnya (Madyawati,2017). Pentingnya pendidikan anak usia dini dapat berpengaruh pada perkembangan anak dalam aspek kecerdasan. Pada masa ini, anak akan membentuk fondasi-fondasi sebagai dasar kepribadian, pembentukan mental dan karakter, rasa ingin tahu yang tinggi, selalu ingin mencoba, serta masa potensial untuk belajar. Masa-masa inilah sering disebut pada masa keemasan pada anak (golden Age) yang artinya apabila anak memperoleh pendidikan yang tepat, maka ia akan mendapatkan kesiapan belajar yang baik yang merupakan kunci sukses bagi keberhasilan anak menghadapi masa depannya.

Anak-anak sejak lahir memiliki kemampuan untuk mengembangkan bicara dan keterampilan berbahasa. Semakin bertambah usia anak maka semakin bertambah pula kemampuan berbahasa anak terutama dalam berbicara (Yuniarti, 2015). Bahasa adalah alat yang digunakan untuk berkomunikasi dengan seseorang baik itu berupa isyarat, ungkapan emosional, bahasa tulisan serta berbicara. Sedangkan bicara adalah suatu pengucapan kata atau bunyi yang mengandung arti untuk menyampaikan ide, gagasan, pikiran kepada orang lain. Pada dasarnya, anak usia dini menyampaikan perasaannya dan apa yang dibutuhkannya dengan berbicara. Kemampuan berbicara anak perlu kita latih sejak usia dini sebagai alat sosialisasi, karena kemampuan berbicara selalu dibutuhkan setiap hari oleh semua orang mulai dari kita bangun tidur hingga akan tidur kembali sebagai sarana untuk berkomunikasi.

Dalam pembelajaran anak usia dini, peran guru dan orang tua sangat penting untuk meningkatkan kemampuan berbicara pada anak. Perkembangan bicara yang berbeda dipengaruhi oleh cara belajar bicara yang berbeda pula. Selain dari cara belajarnya ada banyak faktor yang mempengaruhi adanya perbedaan perkembangan berbicara pada setiap individu. Menurut (Mulyasa, 2012) kemampuan berbicara pada anak usia dini dapat ditingkatkan melalui beberapa cara 
salah satuya dengan proses belajar yang menyenangkan melalui komunikasi, interaksi, sosialisasi, bermain, dan bercerita. Selain itu proses belajar yang efektif juga dapat dilakukan dengan membiarkan anak bermain ditempat bermain umum, dikelas nonformal seperti kelas renang, menanyi, ataau menari dimana dalam satu kelas muridnya beragam dari segi usia sehingga mereka bisa berinteraksi dan belajar satu sama lain. Hal ini akan memberikan kesan yang baik kepada anak pada aktivitas belajarnya, anak akan banyak bertanya dan lebih antusias dalam belajar. Berbeda halnya dengan pembelajaran yang membosankan, monoton, terlalu sulit akan menciptakan kesan yang negatif dan anak akan cepat merasa jenuh (Sadewo, 2019).

Pendidik dalam hal pengembangan bicara pada anak dapat menggunakan metode untuk menyampaikan pesan pembelajaran yang dapat merangsang dan memperbanyak kosa kata anak. Salah satu metode yang digunakan untuk menstimulasi kemampuan berbicara pada anak adalah dengan metode show and tell (Musfiroh, 2011). Menurut (Musfiroh, 2011) Show and Tell adalah suatu metode pembelajaran yang mengutamakan komunikasi sederhana dengan menunjukan benda dan menyatakan pendapat, menungkapkan perasaan, keinginan, maupun pengalaman terkait dengan benda yang ditunjukan. Manfaat metode show and tell adalah anak akan belajar berbicara dan menyimak, menjadi pendengar dan memperkenalkan diri, membuat anak lebih mudah untuk bersosialisasi dengan anak yang lain, praktik bercerita, menambah kosa kata, praktik keterampilan berbincang kritis, mengembangkan empati, mampu untuk memecahkan masalah mengucapkan terimakasih dan mampu meningkatkan rasa percaya diri.

\section{METODE PENELITIAN}

Penelitian ini menggunakan penelitian eksperimental. Desain yang digunakan dalam penelitian ini adalah pra eksperimental dengan rancangan One group pra-post test design. peneliti memberikan pretest (pengamatan awal) terlebih dahulu sebelum diberikan intervensi, setelah itu diberikan intervensi, kemudian dilakukan posttest. Hipotesis dalam penelitian ini dapat dirumuskan menjadi :

Ha : Ada Pengaruh Metode Show and Tell Terhadap Peningkatan Kemampuan 
Berbicara Pada Anak Usia 4-5 Tahun di PAUD Pelita Kasih Singaraja. Ho : Tidak Ada Pengaruh Metode Show and Tell Terhadap Peningkatan Kemampuan Berbicara Pada Anak Usia 4-5 Tahun di PAUD Pelita Kasih Singaraja. Populasi pada penelitian ini adalah anak usia 4-5 tahun di PAUD Pelita Kasih Singaraja sebanyak 30 orang. Pada penelitian ini teknik sampling yang digunakan adalah Nonprobability sampling dengan teknik sampling jenuh. Penelitian ini dilakukan di PAUD Pelita Kasih Singaraja selama 3 minggu. Alat yang dapat digunakan untuk mengumpulkan data pada penelitian ini berupa lembar observasi Denver II untuk pengukuran kemampuan berbicara dan juga SAP metode show and tell. Pada lembar observasi tersebut berisi data demografi sampel dan pengukuran kemampuan berbicara. Dalam data demografi responden terdiri dari nama, usia, kelas, dan jenis kelamin. Pada SAP metode show and tell berisi prosedur pelaksanaan dalam melakukan cerita dengan metode show and tell pada anak, sedangkan pada pengukuran kemampuan berbicara menggunkan format penilaian Denver II yang berbentuk lembar observasi untuk mengetahui kemampuan berbicara pada anak usia 4-5 tahun.

\section{HASIL DAN PEMBAHASAN}

\section{Hasil Penelitian}

Kemampuan berbicara pada anak diukur dengan tugas-tugas perkembangan anak usia 4-5 tahun dalam denver II dan kemudian dicatat dalam lembar observasi. Dalam penelitian ini, peneliti ingin mengetahui kemampuan berbicara pada anak usia 4-5 tahun sebelum (Pre-test) dan sesudah (Post-test) diberikan metode show and tell. Skor kemampuan berbicara sebelum diberikan metode show and tell dapat dilihat pada tabel dibawah ini.

Tabel 1 Gambaran Kemampuan Berbicara responden di PAUD Pelita Kasih Singaraja sebelum diberikan Intervensi

\begin{tabular}{lll}
\hline $\begin{array}{l}\text { Kemampuan } \\
\text { Berbicara }\end{array}$ & Frequensi & $\begin{array}{l}\text { Persentase } \\
(\%)\end{array}$ \\
\hline Advanced & 4 & 13,3 \\
Normal & 8 & 26,7 \\
Caution & 17 & 56,7 \\
Delayed & 1 & 3,3 \\
\hline
\end{tabular}

Pedagogika.fip@ung.ac.id P-ISSN: 2086-4469 E-ISSN: 2716-0580 


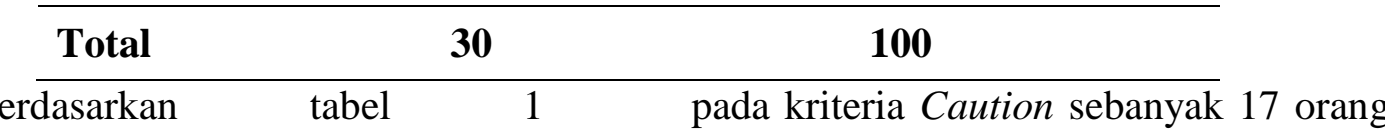

menggambarkan hasil pengukuran

kemampuan berbicara responden

sebelum diberikan metode show and tell

dari tabel tersebut menunjukkan bahwa

dari 30 orang responden, frekuensi

kemampuan berbicara tertinggi berada anak $(56,7 \%)$ dan frekuensi kemampuan

berbicara terendah berada pada kriteria

Delayed sebanyak 1 orang anak $(3,3 \%)$.

Skor kemampuan berbicara sesudah diberikan metode show and tell dapat dilihat pada tabel dibawah ini

Tabel 2. Gambaran Kemampuan Berbicara responden di PAUD Pelita Kasih Singaraja setelah diberikan Intervensi

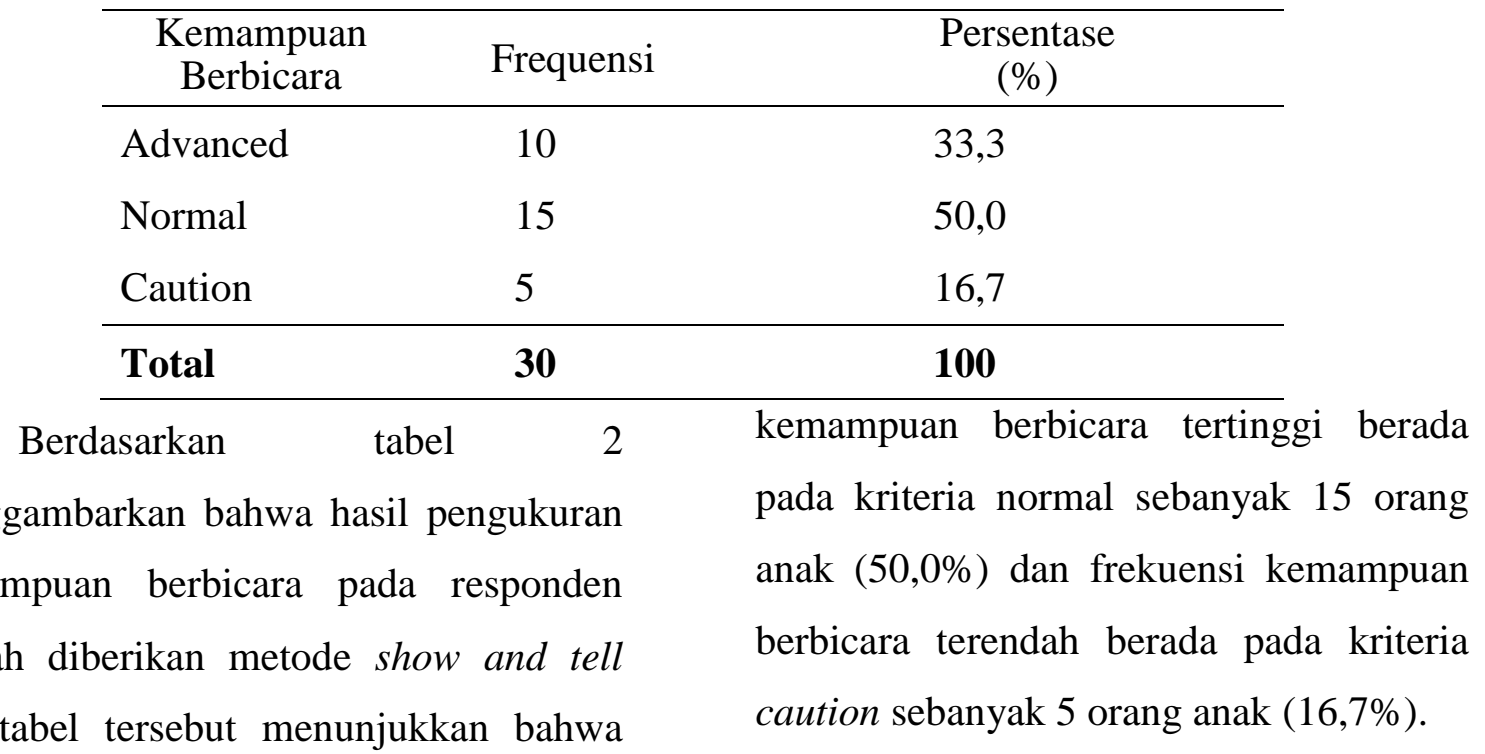

dari 30 orang responden, frekuensi

Tabel 3. Hasil Uji Pre dan Post Test dengan menggunakan Uji Paired T-test

\begin{tabular}{llllll}
\multicolumn{4}{c}{ Paired Differences } & & \\
Mean Std. & Std. & $95 \%$ Confidence & & Sig. \\
Deviation & Error & Interval of the \\
& Mean & Difference \\
& & Lower Upper & & Df & $(2-$ \\
& & & tailed
\end{tabular}

Paired Pre Test

$\begin{array}{lllllllll}\text {-Post Test } & -14.667 & 8.996 & 1.642 & 18.026 & 11.30 & -8.930 & 29 & 0,000\end{array}$

Pedagogika.fip@ung.ac.id P-ISSN: 2086-4469 E-ISSN: 2716-0580 
Berdasarkan tabel 3 uji untuk analisa data pada penelitian ini menggunakan uji Paired Sample T-test yang menunjukkan bahwa hasil sig. (2tailed) atau nilai $\mathrm{p}=0,000$ karena nilai $\mathrm{p}$ lebih kecil dari $0,05 \quad(\mathrm{p}<0,05)$ maka hipotesis nol $\left(\mathrm{H}_{0}\right)$ ditolak dan hipotesis alternatif (H1) diterima. Sehingga dapat disimpulkan bahwa terdapat pengaruh metode show and tell terhadap peningkatan kemampuan berbicara pada anak usia 4-5 tahun di di PAUD Pelita Kasih Singaraja.

\section{Pembahasan}

Karakteristik responden dalam penelitian ini dibagi menjadi 2 karakter yakni : jenis kelamin dan usia. Dalam penelitian ini distribusi frekuensi responden berdasarkan jenis kelamin menunjukkan bahwa dari 30 responden, didapatkan sebagian besar berjenis kelamin laki-laki yaitu sebanyak 17 orang $(56,7 \%)$ sedangkan responden yang berjenis kelamin perempuan sebanyak 13 orang $(43,3 \%)$. Jenis kelamin tidak memiliki pengaruh terhadap perkembangan bicara pada anak. Pada penelitian ini di PAUD Pelita Kasih Singaraja lebih banyak siswa laki-laki dibandingkan dengan siswa perempuan.

Berdasarkan usia menunjukkan bahwa usia tertinggi 5 tahun dan usia terendah 4 tahun, dengan rata-rata usia 4,40 tahun. Usia 4-5 tahun merupakan masa peka, masa sensitif dan masa keemasan (golden age) bagi perkembangan anak. Pada periode emas inilah anak memperoleh proses pendidikan dan mengenali lingkungannya sebagai stimulus terhadap perkembangannya. Salah satu indikator perkembangan yang harus dicapai oleh anak adalah perkembangan bicara (Putriyani, 2012).

Hasil penelitian menunjukan bahwa sebelum diberikan metode show and tell frekuensi kemampuan berbicara responden pada anak usia 4-5 tahun di PAUD Pelita Kasih Singaraja, frekuensi kemampuan berbicara tertinggi berada pada kriteria Caution sebanyak 17 orang anak $(56,7 \%)$ dan frekuensi kemampuan berbicara terendah berada pada kriteria Delayed sebanyak 1 orang anak $(3,3 \%)$.

Anak usia 4-5 tahun berada pada masa keemasan dimana anak mengalami pertumbuhan dan perkembangan. Anak usia 4-5 tahun biasanya sudah dapat mengucapkan kalimat yang terdiri dari empat sampai lima kata. Mereka juga mampu menguasai kata depan seperti dibawah, diatas, disamping, dan didalam. 
Selain itu anak usia 4-5 tahun lebih banyak menggunakan kata kerja dibandingkan kata benda (Syaodih \& Agustin, 2016). Menurut peneliti kemampuan berbicara sangat diperlukan oleh anak dalam melakukan komunikasi baik itu secara langsung ataupun tidak langsung, dan memberikan pengaruh besar bagi penyesuaian sosial dan pribadi pada anak.

Menurut (Arty Nur Mawadah \& Muniroh Munawar Mun, 2018) mengatakan kemampuan berbicara anak dipengaruhi oleh faktor-faktor seperti, faktor internal (umur, kesehatan anak) dan faktor eksternal (lingkungan masyarakat, sosial ekonomi keluarga). Selain itu faktor yang dapat mempengaruhi kemampuan berbicara anak adalah dari faktor bimbingan.

Setelah pemberian perlakuan metode show and tell pada anak usia 4-5 tahun di PAUD Pelita Kasih Singaraja selama 3 minggu, dalam seminggu sebanyak 3 kali pertemuan, peneliti melakukan observasi terhadap kemampuan berbicara pada anak dengan menggunakan lembar observasi denver II, dimana memiliki 10 macam tugas yang harus dilakukan oleh anak. Hasil penelitian menunjukan bahwa setelah diberikan metode show and tell frekuensi kemampuan berbicara responden pada anak usia 4-5 tahun di PAUD Pelita Kasih Singaraja, frekuensi kemampuan berbicara tertinggi berada pada kriteria normal sebanyak 15 orang anak $(50,0 \%)$ dan frekuensi kemampuan berbicara terendah berada pada kriteria caution sebanyak 5 orang anak $(16,7 \%)$.

\section{SIMPULAN}

Metode Show and Tell ini juga dapat meningkatkan rasa kepercayaan diri dan kemampuan menyimak anak. Hal tersebut terlihat setelah kegiatan show and tell anak-anak mau untuk menceritakan pengalamannya dan menyatakan pendapatnya di depan teman-temannya. Menurut hasil yang didapatkkan untuk pengaruh metode show and tell, peneliti menyarankan agar instasi pendidik dapat menjadikan metode show and tell sebagai salah satu kegiatan yang diberikan saat kegiatan belajar mengajar dilakukan.

\section{REFERENSI}

Aisyah, S. (2015). Perkembangan dan Konsep Dasar Pengembangan Anak Usia Dini. (E. Purwanto, Ed.) (1st

\section{Pedagogika.fip@ung.ac.idＰ-ISSN: 2086-4469Ｅ-ISSN: 2716-0580}


ed.). Tangerang Selatan: Universitas Terbuka.

Aprinawati, I. (2017). Jurnal obsesi. Penggunaan Media Gambar Seri Untuk Meningkatkan Kemampuan Berbicara Anak Usia Dini Iis, 1(2), 148-155.

Arty Nur Mawadah \& Muniroh Munawar Mun. (2018). Analisi Peran Ibu Bekerja Dalam Perkembangan Bicara Anak Usia TK B, 3367(2), 56-61.

Kementrian Pendidikan dan Kebudayaan. (2017). Statistik Pendidikan Anak Usia Dini 2016/2017 [Early Childhood Education Statistics 2016/2017], 1-119. Retrieved from http://publikasi.data.kemdikbud.go.i d/uploadDir/isi_C6C3980D-F1F14BEB-8DFA-FD57559F1D86_.pdf

Putriyani. (2012). Tumbuh Kembang Anak Usia Dini, 1110029.

Rahman, U. (2018). Karakteristik Perkembangan Anak Usia Dini. Lentera Pendidikan: Jurnal Ilmu
Tarbiyah Dan Keguruan, 12(1), 4657.

https://doi.org/10.24252/lp.2009v12

$\underline{\text { n1a4 }}$

Soetjiningsih, \& Ranuh, G. (2013). Tumbuh Kembang Anak. (Y. J. Suyono, Ed.) (2nd ed.). Jakarta: EGC

Tania, P. (2018). a. Pengaruh Metode Show And Tell Terhadap Kemampuan Berbicara Anak Kelompok B Di Taman KanakKanak, 6(1).

Wijana, W. D. (2016). Kurikulum Pendidikan Anak Usia Dini. (E. Purwanto, Ed.) (1st ed.). Tangerang Selatan: Universitas Terbuka.

Yuniarti, S. (2015). Asuhan Tumbuh Kembang Neonatus Bayi-Balita Dan Anak Pra-Sekolah. (M. D. Wildani, Ed.). Bandung: PT Refika Aditama.

Yusuf, S., \& Sugandhi, N. M. (2016). Perkembangan Peserta Didik (1st ed.). Jakarta: PT RajaGrafindo Persada. 